\title{
A Study on the Perception of Jordanian EFL Learners' Pragmatic Transfer of Refusals
}

\author{
Ibrahim Fathi Huwari \\ Department of English Language and Translation, Zarqa University, Zarqa, Jordan \\ E-mail: ibrahimhuwari@yahoo.com \\ Yasser Al-Shboul (Corresponding author) \\ Salt College for Human Sciences, Balqa Applied University, Salt, Jordan \\ E-mail: nowshboul@yahoo.com
}

Doi:10.7575/aiac.alls.v.6n.1p.46

URL: http://dx.doi.org/10.7575/aiac.alls.v.6n.1p.46
Received: 16/09/2014

Accepted: 05/02/2015

\begin{abstract}
This study investigates the perception of Jordanian EFL learners' (JEFL) pragmatic transfer of refusal strategies in terms of contextual and cultural factors. Data were collected using a discourse completion test (DCT) and a scaledresponse questionnaire (SRQ) to elicit perception data from the participants. Data from the SRQ were analyzed based on the speaker's right to refuse the initiating act. Findings revealed that the right the speaker has to refuse the initiating act was assigned high ratings by the three groups (i.e., $\mathrm{M}>3.00$ ) in all social categories. Individually, however, the groups displayed the rating value differently where the AEL1 group's perception of the speaker's right was relatively higher than that of the JEFL and JAL1 groups in all the social categories. The JEFL participants' negative pragmatic transfer criteria were met in the first and third social categories. The study concludes with a discussion of important directions for future research.
\end{abstract}

Keywords: Perception, Refusal, Pragmatic transfer, Pragmalinguistic transfer, Sociopragmatic transfer

\section{Introduction}

Over the past two decades, studies (Ramos, 1991; Kasper, 1997; Al-Issa, 1998; Bardovi-Harlig, 1999; Al-Momani, 2009) of interlanguage speech acts have come to realize the importance of pragmatics in second language acquisition, i.e., the need to account for the rules that govern the use of language in context. Not only do second language learners need to know phonology, syntax, and lexicon of a language, they also need to know the rules of speaking. These studies have also revealed that second/foreign language learners have different L2 pragmatic system from the native speakers of the L2, in terms of both perception and production. Gass and Selinker (2001) pointed out that second/foreign language learners rely on their own native language behaviour and culture norms in learning the target language. Thomas (1983) stated that pragmatic transfer occur when speakers use their L1 speech act strategies that are inappropriate in the corresponding of L2 settings. Pragmatic transfer is also operative due to different cross-cultural assessments of size of imposition, taboos, relative power or social distance. With this in mind, the concept of pragmatic transfer in interlanguage pragmatics has received increased attention and has been investigated by a number of applied linguists and ESL/EFL educators. Since researchers disagree about how to define the scope of pragmatics (Kasper, 1992), available definitions of pragmatic transfer therefore varied based on their stance. For example, Kasper (1992) defines pragmatic transfer as the influence that previous pragmatic knowledge has on the use and acquisition of L2 pragmatic knowledge. Specifically, according to Kasper (1992: 207), pragmatic transfer in interlanguage pragmatics is identified as "the influence exerted by learners' pragmatic knowledge of languages and cultures other than L2 on their comprehension, production and learning of L2 pragmatic information”.

Research into the production of speech acts has shown that both similarities and differences exist between native and non native speakers (Beebe et al., 1990; Al-Eryani, 2007; Nelson, Al Batal \& Bakary, 2002; Al-Issa, 1998). Patterns of the strategies or semantic formulas commonly used in the production of the speech acts have received a great deal of attention. However, there is a gap in the perception studies and it has rarely been investigated in interlanguage pragmatic studies. Studies on perception have focused mainly on the speech acts of requests and apologies (Asher \& Simpson, 1994; Cohen, 1996; Thomas, 1983), and among these studies, only one published research has dealt with Jordanian EFL learners (Al-Momani, 2009). The present study is inspired by previous speech act studies on perception (e.g. Tada, 2005; Chen, 2006; Al-Momani, 2009), and it tries to bridge some gaps in interlanguage pragmatics studies. According to the researcher's best knowledge, no study has investigated Jordanian/Arab EFL learners' perception of the speech act of refusal. Previous Jordanian/Arab EFL refusal studies (Al-Issa, 1998; Al-Eryani, 2007; Nelson et al., 2002; Al-Shboul, Maros, \& Yasin, 2012) have focused only on the production of refusal. This will be the major gap where the contribution will be made by this study. Thus, this study examined the speech act of refusal in terms of perception on the perspective of pragmatic transfer. 


\section{The Speech Act of Refusal}

The speech act of refusal, as a face-threatening act, has been identified as a "major cross-cultural stinking point for ESL students" (Takahashi \& Beebe 1987: 133) which can lead to unintended offense and a breakdown in communication. Thus, language learners are most likely to offend their interlocutors when performing the act of refusal because the linguistic obstruction that already exists is further complicated by the face-threatening nature of the speech act. In performing a refusal, which is a dispreferred response, one contradicts the expectations of the interlocutors; therefore, a high level of pragmatic competence is necessary to carry out a refusal felicitously. However, such a competence is particularly difficult for the learners to achieve (Chen, 1996; Al-Shboul et al., 2012). Therefore this speech act of refusal is important to be studied. This study specifically focuses on the speech act of refusal because it is likely to engage the speakers in face-threatening act (FTAs). This speech act also represents one of the most thoroughly researched speech acts in the interlanguage and cross-cultural pragmatic literature (Tada, 2005). Al-Shalawi (1997) stated that an act of refusal may provide an illuminating source of information on the socio-cultural values of a speech community and as significant insights into the social norms that are embedded in cultures. Thus, the speech act of refusal would be an excellent focus for the study of Jordanian and American participants where interlanguage pragmatic transfer is concerned. It will also help raise the awareness of intercultural pragmatics for both groups of participants.

\section{Related Studies on Refusal}

Many studies have been conducted on the speech act of refusal from various perspectives. For example, cross-cultural comparative studies between Japanese and English (Tada 2005), Arabic and English (Nelson et al., 2002), and Arabic and Malay (Al-Shboul et al., 2012). Recently, researches have been conducted to examine the pragmatic and sociocultural transfer (Beebe et al., 1990; Al-Issa, 2003). However, these studies have focused only on the production, none on the perception of refusal. Hence the gap of refusal studies which initiated the present study on the perception of the speech act of refusal. The following paragraphs provide a brief overview of studies conducted on the speech act of refusals in different cultural and linguistic speech communities.

In her study, Tada (2005) examined the development of Japanese EFL learners' pragmatic production and perception of the speech acts of requests, refusals, and apologies using video prompt, which were part of computerized data collection instrument. Production data were collected orally by which the test procedures starting with the video clips sounds and ending with the participant oral responses were recorded. A scaled-response questionnaire was used to elicit participants' perception in the sociopragmatic assessment study. The sample of the study included forty-eight Japanese EFL learners. Results revealed that pragmatic production develops hand in hand with overall English proficiency to some extent, whereas pragmatic perception is relatively independent of proficiency. This tendency was agreed across the three speech acts, across two impositions level, and as a diversity of situations. The researcher concluded that EFL learners need opportunities to practice both perceiving and producing of speech acts by receiving input consisting of English speech acts. This study is particularly important as it is the first of its kind that used video prompt, which were part of computerized data collection instrument. It is also important because it had compared two aspects (perception and production) of pragmatic competence in the same group of learners. This study is related to the present study in terms of data collection instrument as the present study adopted the scaled-response questionnaire from Tada's study. Therefore, the data from this study will be compared with the data of the present study.

In another study, Lee (2008) investigated the perception and production of the speech act of refusals made by Chinese EFL at high and low proficiency levels. For interlanguage and cross-cultural comparison, the data from these two proficiency level were compared with two baseline groups, which are Chinese native speakers and American native speakers. The sample of the study included 60 Chinese EFL learners, 60 native speakers of Chinese, and 60 native speakers of American English. Data were collected using Discourse Completion Tasks to elicit participants' production of refusals. Next, participants were asked to respond whether they feel difficult to refuse the interlocutors in specific situation and whether their refusal would be inappropriate in their culture, which would help to elicit participants' perception about some contextual factors. However, the data used for analysis consisted of 3,345 expressions of refusal elicited from the DCT. Data were analysed based on the classification of refusal strategies initiated by Beebe et al. (1990). It is based on the classification scheme of semantic formulas that includes the three broad categories: direct refusals, indirect refusals and adjuncts to refusals.

Results revealed that the participant of two cultures show a major concern of face when they had to refuse. However, some cross-cultural differences were observed. For example, native speakers of Chinese differentiated in-groups and out-groups obviously under the effect of collectivistic cultures value. In contrast, native speakers of English, under the influence of individualistic cultures value, emphasized on the factor of equality. In addition, both groups of American native speakers and Chinese native speakers preferred indirect strategies more than direct strategies. However, they differ in the content, preference and frequency of refusal strategies. This study is important because it is one of very small number of interlanguage refusal studies looking at both the perception and production of refusals. However, this study has a number of limitations. For example, only written DCT data were discussed in this study. So, this study struggled from the fact that the DCT has its own limitations, therefore role-play or metapragmatic judgment tasks need to be used in order to generalize the results.

Al-Eryani (2007) investigated the speech act of refusal by Yemeni Arabic and American English. The participants of this study consisted of twenty English-speaking Americans, twenty native speakers of Yemeni Arabic and twenty Yemeni advanced EFL learners. All the participants were males, there were no females included. Data were collected using a written DCT. The DCT consisted of six situations in which participants refused offers, requests, invitations, and 
suggestions from someone higher, lower, and equal in status to them. Data were analyzed based on the classification scheme developed by Beebe et al. (1990). Results from the study revealed that American participants tended to be more direct in their refusals when compared to native speakers of Yemeni Arabic. Another difference between the two groups appears in the order of the semantic formulas. However, the EFL learners showed similarities with native speakers of English in three areas: order of semantic formulas, their frequency, and their content. This study is important because it was conducted on Yemeni Arabic dialect which is not often examined in speech act research. Nonetheless, this study struggled from the fact that the DCT has its own limitations, therefore naturalistic settings need to be used in order to generalize the results.

In the Jordanian context, Al Issa (2003) examined the realization patterns of refusal strategies by Jordanians and Americans. The main concern of this study was to investigate if there was evidence of pragmatic transfer from Arabic to English and the reasons causing this transfer. Data were collected using a written DCT followed by semi-structured interviews with the Jordanian EFL learners. These interviews were conducted in order to find out the motivating factors for pragmatic transfer from L1. The results showed evidence of pragmatic transfer in terms of frequency, type, number, and content of the semantic formulas used. Moreover, compared to the American use of refusals, the Jordanian participants tend to refuse in lengthy, elaborate ways and use less direct strategies, especially when the interlocutor was of a higher social status. Al-Issa's study is particularly important because the DCT used in his study was designed and further developed by the researcher based on naturally occurring refusal data that were collected through observation and field work. Al-Issa's DCT situations were also adopted for the present study. However, Al-Issa's study has focused only on the production of the speech act of refusal neither on elicitation data on how the participants perceive the speech act of refusal. This will be a gap where the contribution will be made by this study.

Finally, Al-Shboul et al. (2012) investigates the similarities and differences of the speech act of refusals in English between Jordanian English as a Foreign Language (EFL) and Malay English as a Second Language (ESL) postgraduate students. Data were collected using a modified version of the Discourse Completion Test (DCT) initially developed by Beebe et al. (1990). To obtain responses as natural as real-life communication, an interviewer audiotaped and read the situations aloud to both groups in English to enable the participants to respond verbally to situations. Data were analyzed in terms of semantic formulaic sequences and were categorized by four trained coders based on the classification of refusal strategies established by Beebe et al. (1990). Results revealed that both groups used almost similar strategies with similar frequency in performing refusals. For example, the most frequently used refusal strategies by the Jordanian and Malay participants were excuse, reason, explanation, and expressing statement of regret. However, they differed in the use and frequency count of indirect strategies with the Malays using less indirect strategies than the Jordanians. In addition, the results indicate that the Jordanian participants expressed 'gratitude' less frequently than the Malay participants when refusing invitations by equal and lower status person. Similar results were found when performing refusal in all request situations. This study is important as it is the first study that investigated the similarities and the differences between Jordanian Arabic and Malaysian Malay on the speech act of making refusals, both groups are NNS of English. In addition, this study is important because it is related to the present study in terms of its sample as both of these studies deal with Jordanian postgraduate students in Malaysia. However, as is the case with Arabic refusal studies, this study has focused only on the production of the speech act of refusal neither on perception data.

The studies reviewed above used the DCT to collect the data which is the instrument that elicited single-turn responses. Therefore, such single-turn responses do not reflect real-life interactions and do not give information on how refusals are negotiated over a number of turns. It can be also seen that all of the previous studies showed above used a written DCT with the exception of Al-Shboul et al.'s (2012) study who conducted an oral DCT by eliciting the data orally. The findings of the previous studies reviewed above are mostly consistent. For instance, Al-Issa (2003), Al-Eryani (2007), and Al-Shboul et al. (2012), found that Arabs tended to use more indirect strategies in their refusals. In Lee's (2008) study, both groups of American native speakers and Chinese native speakers preferred indirect strategies more than direct strategies. Regarding the studies examining the language learner (Al-Issa, 2003; Al-Eryani, 2007; Lee, 2008), they all reported evidence of negative pragmatic transfer from L1. While Tada (2005) and Lee (2008) investigated the perception and production of the speech act of refusals, Jordanian/Arab EFL learners' studies have focused only on the production of the speech act of refusals. More specifically, although there has been some research on Jordanian EFL learners in interlanguage pragmatics, their focus were on production only. Thus, the present study will add empirical findings in terms of the perception of refusal by Jordanian EFL learners.

\section{The Study}

This study is designed to investigate the perception of Jordanian English as Foreign Language (JEFL) speakers' pragmatic transfer of refusal strategies in terms of contextual and cultural factors. The aim is to help establish a better understanding of the speech act and promote socio-pragmatic awareness in the use of English language among JEFL speakers. It is primarily based on Kasper's (1992) pragmatic transfer theory. She defines pragmatic transfer as the influence that previous pragmatic knowledge has on the use and acquisition of L2 pragmatic knowledge. According to Kasper (1992: 207), pragmatic transfer in interlanguage pragmatics is identified as "the influence exerted by learners' pragmatic knowledge of languages and cultures other than L2 on their comprehension, production and learning of L2 pragmatic information". Kasper (1992) proposed two kinds of transfer: sociopragmatic transfer and pragmalinguistic transfer. Sociopragmatic transfer is operative when the social perceptions underlying language users' interpretation and performance of linguistic action in L2 are influenced by their assessment of subjectively equivalent L1 contexts (Kasper 
1992: 209). Thus, context-external factors such as social status, social distance, etc. and context-internal factors which inherent to speech act such as the size of difficulty, right and obligation of refusal should be taken into consideration. In contrast, pragmalinguistic transfer shall designate the process whereby the illocutionary force or politeness value assigned to particular linguistic material in L1 influences learners' perception and production of form-function mappings in L2 (Kasper 1992: 209).

The two kinds of pragmatic transfer can be further divided into two subtypes: positive or negative transfer. The positive pragmatic (or facilitation) happens when L1 pragmatic knowledge supports in the comprehension, production, and acquisition of L2 pragmatic information. Hence, an effective interaction in the target language can be referred to learners' reorganization of common features between their L1 and L2. Thus, such kind of transfer is regarded as evidence of universality among languages. Yet, positive transfer does not necessary improves of communicative success (Žegarac \& Pennigton, 2000) as there are language-specific elements. On the other hand, Kasper and BlumKulka (1993:10) refer negative pragmatic transfer (or interference) to "the influence of L1 pragmatic knowledge which differs from the L2." Thus, learners may perform a speech act inappropriately because they have transferred their L1 features and norms in the target language, which are therefore inappropriate in that target language. As a result, a pragmatic failure or being unable to understand the meaning of an utterance is most likely to occur (Liu, 1997). According to El Samaty (2005), learners' judgment of a language specific element as universal is the reason of negative transfer. In the present study, negative pragmatic transfer is operational if there is a statistically significant difference between the JAL1 and AEL1 groups and between the JEFL and AEL1 groups and no statistically significant difference between the JAL1 and JEFL groups. Thus, the study attempts to address the following research questions:

1. What are the similarities and differences in the speaker's right perception of refusals by JEFL learners compared to AEL1 and JAL1?

2. Would pragmatic transfer from Arabic to English take place in Jordanian EFL learners' perception of the right they have to refuse the act?

\section{Methodology}

\subsection{Participants}

For the purpose of the present study, data were collected from three different groups of Jordanian graduate students at University Kebangsaan Malaysia (henceforth, UKM), Malaysia, and American native speakers of English at State of Ohio, USA. The first group was the target group, consisting of 30 Jordanian intermediate JEFL learners. The second and third groups were reference groups, consisting of 15 American English Language (AEL1) speakers and 15 Jordanian Arabic Language (JAL1) speakers. The participants' ages range from 30-40 years old. Both groups of Jordanian were from northern region of Jordan who are pursuing different academic majors (e.g. Islamic studies, Arabic, History, pure science, applied science) excluding English language or linguistics. While JAL1 participants responded to the Arabic version because they have a low English proficiency level which is related by their educational background at the Bachelor degree level, both groups of JEFL and AEL1 participants responded to the English version. Unlike JAL1 group, some of the participants in the JEFL group have TOEFL or IELTS and some of them passed the English Placement Test at UKM. Hence proficiency was determined based on their scores of the institutional TOEFL, IELTS, or English Placement Test scores, and therefore were judged to represent intermediate English proficiency. None of JEFL participants have ever travelled to the U.S. or to any other English-speaking country as this is important to eliminate any linguistics influence might they have other than their native language (Arabic). The study included only male participants because it was conducted abroad, in Malaysia, where very few Jordanian female graduate students could be found. In order to match the sex ratio, only male white native speakers of American English whose parents are also native speakers of American English were invited to participate in the present study.

\subsection{Instrument and Procedure}

The issue of how data are collected is one of the main concerns in interlanguage researches. Trosborg (1995) stressed that data collection in an ethnographic procedure (i.e. naturally occurring data) is the ultimate goal in most crosscultural researches. This data collection method is considered to be the most reliable data source in speech act research because it reflects what speakers actually say rather than what they think they will say in a given speech situation (Bardovi-Harlig \& Hartford, 1993). However, the contextual variables (e.g., gender, age, status) are difficult to be controlled and very time consuming. Another limitation is that the occurrence of some speech acts cannot be predicted and therefore this method might not yield enough instances of a particular speech act. Accordingly, collecting ethnographic data seem to be an unlikely option for interlanguage speech act researches.

In the present study, the researcher combined eleven situations (from originally of 15 situations) of Al-Issa's (1998) Discourse Completion Test (DCT) and Tada's (2005) Scaled-response Questionnaire (SRQ) as a controlled instrument in order to elicit refusal perception from the three selected groups. As shown in table 1, The DCT consists of three groups of situations: 3 requests, 4 invitations/offers and 4 suggestions. Two different variables were manipulated to represent the relationship between the speaker and the hearer in each group of situations: social status (higher, lower, equal) and social distance (close, familiar, distance). The SRQ question (Do you have a right to refuse the suggestion, requests, invitations/offers?) remained constant under each DCT situation. The same modification was made to the 
Arabic version to be completed by the Jordanian Arabic native speakers. While the researchers adopted two versions (i.e., Arabic and English) of Al-Issa's (1998) DCT, only English version of Tada's SRQ is available. Hence, this version was translated into Arabic by the researchers of the present study, who are native speakers of Jordanian Arabic. Accuracy of translation was then checked by two Jordanian graduate students in linguistics.

Table 1. Classification of the DCT

\begin{tabular}{lllll}
\hline DCT \# & $\begin{array}{l}\text { Stimulus } \\
\text { type }\end{array}$ & $\begin{array}{l}\text { Refuser's } \\
\text { status }\end{array}$ & $\begin{array}{l}\text { Refuser's } \\
\text { distance }\end{array}$ & Situations \\
\hline 3 & Request & Equal & Distance & Student asking to watch his/her books \\
7 & Request & Lower & Familiar & Professor asking for assistance \\
9 & Request & Higher & Close & High-school relative asking for help in homework \\
2 & Invitation & Higher & Familiar & Freshman inviting you for lunch \\
4 & Invitation & Lower & Familiar & Professor inviting you to attend a lecture \\
8 & Offer & Equal & Distance & Stranger offering you a ride \\
10 & Offer & Equal & Close & Friend offering you some money \\
1 & Suggestion & Lower & Familiar & Faculty advisor suggesting a course in writing \\
5 & Suggestion & Equal & Distance & Student suggesting a course with a professor \\
6 & Suggestion & Equal & Close & Friend suggesting a topic \\
11 & Suggestion & Higher & Familiar & Food server suggesting chicken dish \\
\hline
\end{tabular}

Regarding the JAL1 and JEFL groups, the researchers administrated the questionnaire at UKM's main campus located in Bandar Baru Bangi, a town in the state of Selangor, Malaysia. The researchers met the JAL1 group at different locations in UKM's main campus such as library and their faculties to administrate the questionnaire. Regarding the JEFL group, the researchers met the participants and administered the questionnaires at seven computer laboratories from 3 faculties/institutes, namely the Faculty of Information Science and Technology, the Institute of Bioscience and Biotechnology Studies, and the Institute of Mathematical Science Studies. The researchers briefly explained the purpose of this research in English language and participants' native language (Arabic) for JEFL group and in Arabic language for JAL1 group. Then the researchers gave a soft copy of the questionnaire including background information via email or using data-traveller. Participants were then asked to read each situation and react to it by trying to place themselves into the situations presented.

For the AEL1 group, a research assistant was hired to administrate the questionnaire at U.S. Thus, one Jordanian man worked as an assistant. This male Jordanian is a friend of the researchers, having graduated from the same universities (i.e. Al Al-Bayt University in Jordan for bachelor's degree and University Utara Malaysia in Malaysia for master's degree). He was working at the State of Ohio at the time of the data collection. The assistant's academic background facilitated the process of training him. The research assistant had finished his master thesis in speech act studies. He has experience of collecting such data as well as he was familiar with sociolinguistics and interlanguage methodologies. The research assistant was asked to collect data from male white native speakers of American English whose parents are also native speakers of American English. The way how questionnaires were distributed to AEL1 was the same as how it was done to JEFL group (i.e. via email or using data-traveller), but at different places such as an advertising company, homes, and a public garden. Over six weeks, the research assistant collected fifteen questionnaires for the present study. Finally, there was no time limitation for the participants to complete questionnaires as language proficiency was not the focus in the present study.

\subsection{Data Analysis}

A major part of the analysis of speaker's right perception data was conducted on the social categorical level, combining the 11 DCT situations into five social categories based on the systematic variation of social power (P) and social distance (D). The combination of the 2 variables yielded five social categories: category $1(-p,=D)$, which includes situations 1 (faculty advisor suggesting a course in writing), 4 (professor inviting you to attend a lecture), and 7 (professor asking for assistance); category $2(+\mathrm{p},=\mathrm{D})$, which includes situations 2 (freshman inviting you for lunch) and 11 (food server suggesting chicken dish); category $3(=\mathrm{p},-\mathrm{D})$, which includes situations 3 (student asking to watch his/her books), 5 (student suggesting a course with a professor) and 8 (stranger offering you a ride); category 4 ( $=\mathrm{p}$, $+\mathrm{D}$ ), which includes situations 6 (friend suggesting a topic) and 10 (friend offering you some money); and category 5 $(+\mathrm{p},+\mathrm{D})$, which includes situations 9 (high-school relative asking for help in homework).

To ensure the reliability of coding of the data obtained from the SRQ, three raters (i.e. two majored in applied linguistics and are well-trained in the analysis of speech acts coding schema and one majored in computer since and is expert in the statistical software SPSS 17.0) worked cooperatively in order to enter the data to the statistical software SPSS. Adopting the statistical software SPSS 17.0, the results of SRQ were analyzed by statistical methods of ANOVA and Tukey HSD post hoc tests, which are the most appropriate tests to analyse such data (Brown, 1988; Chen, 2006; Al- 
Momani, 2009). In other words, the ANOVA was chosen for this examination because researchers have found it the appropriate statistical technique to use when examining the significance of group differences for one continuous dependent variable and one discrete independent variable (Al-Momani, 2009). Moreover, Tukey honest significant differences (HSD) post hoc analysis were performed to determine whether there were significant differences between the AEL1 and JEFL groups in their assessment of the right they have to refuse the act and whether negative pragmatic transfer had occurred.

\section{Results}

Researchers (e.g., Blum-Kulka \& House, 1989; Chen, 1996; Chen, 2006; Lee, 2008; Al-Momani, 2009) have found that speakers' differing perceptions of the weight and values of contextual variables (e.g., difficulty, right, obligation, and power) is an aspect of cross-cultural variation that may influence speech act production. Thus, the goal of this study is twofold: first, to investigate the similarities and differences in the perception of refusals by Jordanian EFL learners (JEFL) compared to American English native speakers (AEL1) and Jordanian Arabic native speakers (JAL1) with regard to the right they have to refuse the act. Second, to investigate whether pragmatic transfer from Arabic to English takes place in JEFL learners' perception of the right they have to refuse the act. A scaled response-questionnaire (SRQ) was used to assess the AEL1, JEFL, and JAL1 groups' perception of the right the speaker had to refuse the initiating act. The participants were instructed to assess the variable on a 5-point Likert scale ranging from $1=$ the lowest to $5=$ the highest.

The Scaled-response data obtained from the 30 JEFL, 15 AEL1, and 15 JAL1 were computed on SPSS 17.0 (ANOVA and Tukey honest significant differences (HSD) post hoc analysis). Table 2 illustrated the overall comparison of the AEL1, JEFL, and JAL1 groups' responses to the five social categories.

Table 2. ANOVA results for speaker's right by group in the five social categories

\begin{tabular}{|c|c|c|c|c|c|c|c|c|c|}
\hline \multirow{2}{*}{$\begin{array}{l}\text { Social } \\
\text { Category }\end{array}$} & \multicolumn{2}{|l|}{ JEFL } & \multicolumn{2}{|l|}{ JAL1 } & \multicolumn{2}{|l|}{ AEL1 } & \multirow{2}{*}{$\begin{array}{l}\text { df } \\
\text { (Error) }\end{array}$} & \multirow[b]{2}{*}{$\mathrm{F}$} & \multirow[b]{2}{*}{ Sig. } \\
\hline & Mean & $\begin{array}{l}\text { Std. } \\
\text { Dev. }\end{array}$ & Mean & $\begin{array}{l}\text { Std. } \\
\text { Dev. }\end{array}$ & Mean & $\begin{array}{l}\text { Std. } \\
\text { Dev. }\end{array}$ & & & \\
\hline $\mathrm{C} 1(-\mathrm{p},=\mathrm{D})$ & 3.58 & 0.86 & 3.11 & 0.78 & 4.51 & 0.63 & $2(57)$ & 12.479 & $0.000 * \mathrm{~T}$ \\
\hline $\mathrm{C} 2(+\mathrm{p},=\mathrm{D})$ & 4.35 & 0.73 & 4.23 & 0.62 & 4.80 & 0.46 & $2(57)$ & 3.368 & $0.041^{*}$ \\
\hline $\mathrm{C} 3(=\mathrm{p},-\mathrm{D})$ & 4.31 & 0.63 & 4.22 & 0.61 & 4.89 & 0.30 & $2(57)$ & 6.675 & $0.002 * \mathrm{~T}$ \\
\hline $\mathrm{C} 4(=\mathrm{p},+\mathrm{D})$ & 4.33 & 0.70 & 3.83 & 0.99 & 4.77 & 0.32 & $2(57)$ & 6.342 & $0.003 *$ \\
\hline $\mathrm{C} 5(+\mathrm{p},+\mathrm{D})$ & 4.43 & 0.90 & 4.13 & 1.19 & 4.67 & 0.49 & $2(57)$ & 1.320 & 0.275 \\
\hline
\end{tabular}

Note: $\mathbf{T}$ indicates the occurrence of negative pragmatic transfer. ${ }^{*} \mathrm{p}<0.05$

As shown in Table 2, the right the speaker has to refuse the initiating act was assigned high ratings by the three groups (i.e., $M>3.00$ ) in all social categories. Individually, however, the groups displayed the rating value differently where the AEL1 group's perception of the speaker's right was relatively higher than that of the JEFL and JAL1 groups in all the social categories. The results of the ANOVA for the five categories confirmed this observation, demonstrating significant mean differences in category $1(F[2,57]=12.479, p=.000)$; category $2(F[2,57]=3.368, p=.041)$; category $3(F[2,57]=6.675, p=.002)$, and category $4(F[2,57]=6.342, p=.003)$.

Tukey HSD post hoc pair comparisons revealed that the JEFL group's $(M=4.35)$ assessment of the speaker's right in category 2 was significantly higher than that of the JAL1 $(M=4.23)$ but significantly lower than that of the AEL1 group $(M=4.80)$. In addition, the JEFL group's $(M=4.33)$ assessment of the speaker's right in category 4 was significantly higher than that of the JAL1 $(M=3.83)$ but significantly lower than that of the AEL1 group $(M=4.77)$, a pattern that indicates development towards the target culture's sociopragmatic knowledge and L1 influence. On the other hand, negative pragmatic transfer criteria were met in the first and third categories. While there were no significant differences between the JEFL and JAL1 groups in category $1(M=3.58$ and $M=3.11$, respectively), and category $3\left(M=4.31\right.$ and $M=4.22$, respectively), both groups ${ }^{\text {ee }}$ assessment of the speaker's right in these two categories was significantly lower than that of the AEL1 group $(M=4.51$, and $M=4.89$, respectively).

\section{Discussion}

Research question one was formulated in order to find out if there are similarities and differences in the perception of refusals by JEFL learners compared to AEL1 and JAL1 with regard to the right they have to refuse the act. Similar perceptions of contextual variables were found when compared to either study by Al-Momani (2009), Tada (2005), Chen (2006), and Blum-Kulka et al. (1989). Generally, the findings show the existence of a universal perception knowledge that is shared by members of different cultures. This observation was drawn based on the fact that the three participating groups followed a similar pattern in their assessment of the 5 social categories; all three groups assigned high ratings (i.e., $M>3.00$ ) for the speaker's right to refuse an initiating act. This is in accordance with those reported 
by Al-Momani (2009), who found that all three groups (JEFL, AE and JA) differentiated between familiar and unfamiliar situations and between high and low power situations. In another study, Blum-Kulka et al. (1989) found that native speakers of Hebrew, German, and Argentinean Spanish followed the same criteria in assessing familiarity, power, difficulty, right, and obligation.

In terms of the differences, the AEL1 group's perception of the speaker's right was relatively higher than that of the JEFL and JAL1 groups in all the social categories (see Table 2). Significant reasons for this difference are related to the phenomenon of pragmatic transfer and cultural values as explained below.

Research question two was set in order to examine if pragmatic transfer from Arabic to English takes place in JEFL learners' perception of the right they have to refuse the act. Based on the assumption that pragmatic transfer is an existence phenomenon in the speech act perception and production of non native speakers, Kasper (1992: 207), identified pragmatic transfer as "the influence exerted by learners' pragmatic knowledge of languages and cultures other than L2 on their comprehension, production and learning of L2 pragmatic information." Hence, the JEFL and AEL1 participants demonstrated a culturally specific perception of contextual variables in 4 out of 5 social categories namely categories $1,2,3$, and 4 . The criterion where the occurrence of negative pragmatic transfer is concerned was met in the first and third social categories as shown in Table 2 above.

The reason that both Jordanian groups assessed their right of making the refusal as being weaker than that of the AEL1 participants reflects deeply rooted cultural values. That is, whereas American culture emphasizes the role of the individual and his or her rights and obligations which is a main characteristic of individualistic culture, the hierarchical structure of the Jordanian culture emphasizes the group, group harmony, and social hierarchy which are a main characteristic of collectivist culture (Gudykunst \& Ting-Toomey, 1988; Ting-Toomey, 1999). For example, in situation 1 , in which faculty advisor suggesting a course in writing, situation 4 in which professor inviting you to attend a lecture, and situation 7 in which professor asking for assistance, it can be assumed that an American participant in the more equalitarian American learning environment would be more likely to perceive himself or herself as having a stronger right to make a refusal than would a Jordanian participant in the more hierarchical Jordanian learning context. These results accorded with those reported by Hill (1997), who found that Japanese learners of English tended to assess their right of making a request as significantly weaker than that of native British English speakers. Moreover, Al-Momani (2009) found that both Jordanian groups assessed their right of making the request as being weaker than that of the $\mathrm{AE}$ participants. The criteria where negative pragmatic transfer is concerned were met for three of the five situations in which the JEFL participants assessed this variable. Hence, Al-Momani attributed such difference between the Jordanian groups and the $\mathrm{AE}$ group regarding the speaker's right to reflect deeply rooted cultural values.

To sum up, both similarities and differences in the perception of refusals by JEFL were found as compared to American English native speakers (AEL1) and Jordanian Arabic native speakers (JAL1). Also, pragmatic transfer from Arabic to English occurs in JEFL learners' perception of the speaker's right. That is, the JEFL and AEL1 participants demonstrated a culturally specific perception in 4 out of 5 social categories. Further, the criterion where the occurrence of negative pragmatic transfer is concerned was met in the first and third social categories. In these categories, JEFL participants differed from AEL1 participants' norms, reflecting the norms given by JAL1 participants, indicating native language influence.

\section{Limitations and Further Research}

While this study has generally answered the proposed research questions, further research on refusal realizations by Jordanian and American participants need to be investigated. The generalizability of findings may be constrained by the following considerations.

The participants for this study were recruited from one region in Jordan (i.e. north region) and one region in the United States (i.e. State of Ohio). As regional dialects were not accounted for, the native speaker participants may not have been representative of all native Jordanian Arabic speakers or native American English. In addition, the sample size only involved a small number of male participants whose age ranged from thirty to forty years. Population with different educational backgrounds, gender, and age groups could have given different results. Hence, these findings should be considered tentative and possibly not applicable to other contexts or participants with different characteristics. Moreover, the JEFL participants were recruited from only one university in Malaysia; whether other JEFL learners from other schools demonstrate the same refusal tendencies should be confirmed by future research. Finally, the participants' length of stay in Malaysia was not controlled for. Participants with different length of stay could have been in the same group. Hence, JEFL learners with different length of stay exhibit the same refusal tendencies should also be confirmed by future research.

Since the present study was the first refusal study, according to the researcher's best knowledge, that focused on perception of refusals among Jordanian/Arab EFL learners, there is certainly a need for more studies that investigate the scope of this research. Findings of such studies would provide very useful insights of how English speech acts are realized by Jordanian/Arab EFL learners. In addition, such findings would provide an invaluable resource for Arabic teachers of English, Arabic textbook writers, and curriculum designers. Researchers are also encouraged to replicate this study using different data collection methods, such as role-plays or ethnographic observation which would provide more insight into the advantages and disadvantages of each data collection method, leading to the development of a more grounded approach to speech act studies. Future researchers who are interested in interlanguage studies are also encouraged to start where this study ended. That is, some of the present study limitations could be addressed by those 
researchers through including situations representing a greater number of social settings (e.g., the street, home, workplace, or market). Moreover, JEFL learners at different proficiency levels (e.g., beginner, intermediate, and advanced) should be examined in future researches. This would provide useful insights on the role of second language proficiency on the perception of refusals. This also would allow future researchers to know whether pragmatic features are developmental or remain with learners even at advanced stages. Future researchers could also control for a number of variables that have been found to be significant in speech act research such as gender. Hence, it would be important to find out in what ways the variable of gender affects the realization of refusals speech acts. Investigating how gender interacts with other variables, such as social status and social distance, would also produce valuable data. As the number of participants in this study was not very large and it consisted entirely of male participants, future researchers could replicate this study with a wider number of participants to determine if such variable could have given different results.

In conclusion, the present study has contributed to our understanding of how the speech act of refusal is perceived by three culturally and linguistically diverse groups (JEFL, AEL1, and JAL1). It also has been shown that speech acts reflect the cultural norms and values that are possessed by speakers of different cultural backgrounds, as different cultures are very likely to realize speech acts quite differently. Such differences might cause misunderstanding or communication breakdowns when people from different cultural backgrounds come in contact with each other. Finally, the presents study has revealed important findings that would be useful in studied in intercultural and interlanguage comparisons.

\section{References}

Al-Eryani, A. A. (2007). Refusal Strategies by Yemeni EFL Learners. The Asian EFL Journal 9 (2): 19-34.

Al-Issa, A. (1998). Socio-pragmatic transfer in the performance of refusals by Jordanian EFL learners: Evidence and motivating factors. Unpublished PhD dissertation. University of Pennsylvania, USA.

Al-Issa, A. (2003). Socio-cultural transfer in L2 speech behaviours: Evidence and motivating factors. International Journal of Intercultural Relations (27): 581-601.

Al-Momani, H. S. (2009). Caught Between Two Cultures: The Realization of Requests by Jordanian EFL learners. Doctoral dissertation. Indiana University of Pennsylvania, USA.

Al-Shalawi, H. (1997). Refusal strategies in Saudi and American culture. Unpublished master's thesis. Michigan University, USA.

Al-Shboul, Y. Maros, M. \& Yasin, M.S.M. (2012). An Intercultural Study of Refusal Strategies in English between Jordanian EFL and Malay ESL Postgraduate Students. $3 L$ The Southeast Asian Journal of English Language Studies 18, (3): 29-39.

Asher, R. E. \& Simpson. J. M. (Eds.). (1994). The Encyclopaedia of Language and Linguistics (6), pp 3267. Oxford. Pergamon Press.

Bardovi-Harlig, K., \& Hartford, B. S. (1993). Refining the DCT: Comparing open questionnaires and Dialogue Completion Tasks [Monograph]. Pragmatics and Language Learning (4):143-165.

Bardovi-Harlig, K. (1999). Researching method. In L. F. Bouton (Ed.), Pragmatics and language learning (Vol. 9, pp. 237-264). Urbana-Champaign: University of Illinois.

Beebe, L.M. Takahashi, T. \& Uliss-Weltz, R. (1990). Pragmatic transfer in ESL refusals. In R. C. Scarcella, E. S. Anderson, and S. D. Krashen (Eds.), Developing communicative competence in a second language (pp. 55-94). New York: Newburry House.

Blum-Kulka, S. \& House, J. (1989). Cross-cultural and situational variation in requesting behavior. In S. Blum-Kulka, J. House, \& G. Kasper (Eds.), Cross-cultural pragmatics: Requests and apologies (pp. 123-154). Norwood, NJ: Ablex.

Blum-Kulka, S., House, J., \& Kasper, G. (1989). Cross-cultural pragmatics: Requests and apologies. Norwood, NJ: Ablex.

Brown, P. (1988). Understanding Research in Second Language Learning: A Teacher's Guide to Statistics and Research Design. New York: Cambridge University Press.

Chen, H. (1996). Cross-cultural comparison of English and Chinese metapragmatics in refusal. Unpublished PhD dissertation, Indiana University, USA.

Chen, M. (2006). A Study of Chinese EFL Interlanguage Requests. Master's Thesis. National Sun Yat-sen University.

Cohen, A. (1996). Speech act. In S. L. Mckay, \& N. H. Horeberger (Eds.). sociolinguistics and language teaching (pp. 393-420). Cambridge: Cambridge University Press.

El-Samaty, M. (2005). "Helping foreign language learners become pragmatically competent", Proceedings of the 10th Arab World English Journal TESOL Arabia Conference, 9.

Gass, S. M. \& Selinker, L. (2001) Second Language Acquisition: An Introductory Course. London: Lawrence Earlbaum.

Gudykunst, W. B., \& Ting-Toomey, S. (1988). Culture and interpersonal communication. Newbury Park, CA: Sage. 
Hill, T. (1997). The development of pragmatic competence in an EFL context. Unpublished doctoral dissertation, Temple University, Japan

Kasper, G. (1992). Pragmatic transfer. Second Language Research, 8, (3): 203-231.

Kasper, G. \& Blum-Kulka, S. (1993). Interlanguage Pragmatics. New York, NY: Oxford University Press.

Lee, C. (2008). An Interlanguage Study of the Speech Act of Refusals made by EFL Learners in Taiwan. Master's thesis. National Sun Yat-sen University.

Liu, F. (1997). An aspectual analysis of ba. Journal of East Asian Linguistics (6): 51-99.

Nelson, Al-Batal, \& Echols. (2002). Directness vs. indirectness: Egyptian Arabic and US English communication style. International Journal of Intercultural Relations (26) 39-57.

Ramos, J. (1991). "No...because": A Study of Pragmatic Transfer in Refusal Among Puerto Rican Teenagers Speaking English. Unpublished Doctoral Dissertation. Colombia University Teachers Collage. Colombia.

Tada, M. (2005). Assessment of EFL Pragmatic Production and Perception Using Video prompts. Unpublished Doctoral Dissertation. Temple University Graduate Bored, USA.

Thomas, J. (1983). Cross-cultural pragmatic failure. Applied Linguistics (4): 91-112.

Ting-Toomey, S. (1999). Communicating across cultures. New York: Guilford Press.

Trosborg, A. (1995). Interlanguage pragmatics. Requests, complaints and apologies. Berlin: Mouton de Gruyter.

Zegarac, V. \& Pennington, M. C. (2000). Pragmatic transfer in intercultural communication. In H. Spencer-Oatey (Ed.). Cultural speaking: managing rapport through talk across cultures (pp.165-190). New York: Continuum. 